Urol Int 1991;46:241-243

\title{
Contents, Vol. 46, No. 3, 1991
}

\section{Contents}

Introduction

Tanagho, E.A.; Carroll, P.R 245

Quality of Life: How Is It Measured and Defined?

Breslin, S 246

Pain Management for Urological Malignancies

McKay, W.R 252

Impotence after Radical Pelvic Surgery: Physiology and Management

Lue, T.F 259

Nerve Sparing and Continence Preservation during Radical ProstatectomyNarayan, P 266

The Value of Screening for Prostatic Carcinoma: A Commentary

Hinman, F.,Jr 275

Organ Preservation in the Management of Pelvic Rhabdomyosarcoma

Massad, C.A.; Kogan, B.A.; Ablin, A.R 279

Use of the Ileocecal Segment for Bladder Substitution or ContinentUrinary DiversionCarroll, P.R.; McAninch, J.W 283

Surveillance for Clinical Stage I Nonseminomatous Testis Carcinoma: Rationale and Results Stephenson, R.A 290

Stage A Nonseminomatous Testis Carcinoma: Rationale and Results ofNerve-Sparing

Retroperitoneal LymphadenectomyFoster, R.S.; Donohue, J.P.; Bihrle, R 294

Assessment of Risk in Metastatic Testis Carcinoma: Impact on Treatment

B. Bajorin

F.; Geller

N.L.; Bosl

G.J 298

Use of Biological Response Modifiers for Management of Renal CellCarcinomaWilkinson

M.; Aronson

F 304 